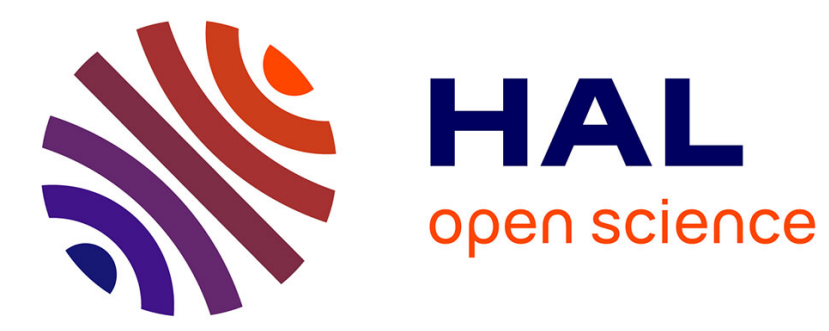

\title{
HIGH SPIN STATES OF THE ODD-ODD 110In NUCLEUS
}

\author{
R. Béraud, A. Charvet, R. Duffait, M. Meyer, J. Genevey, J. Tréherne, A. \\ Genoux-Lubain, F. Beck, T. Byrski
}

\section{- To cite this version:}

R. Béraud, A. Charvet, R. Duffait, M. Meyer, J. Genevey, et al.. HIGH SPIN STATES OF THE ODDODD 110In NUCLEUS. International Conference on Nuclear Behaviour at High Angular Momentum, 1980, Strasbourg, France. pp.C10-159-C10-162, 10.1051/jphyscol:19801017 . jpa-00220636

\section{HAL Id: jpa-00220636 https://hal.science/jpa-00220636}

Submitted on 1 Jan 1980

HAL is a multi-disciplinary open access archive for the deposit and dissemination of scientific research documents, whether they are published or not. The documents may come from teaching and research institutions in France or abroad, or from public or private research centers.
L'archive ouverte pluridisciplinaire HAL, est destinée au dépôt et à la diffusion de documents scientifiques de niveau recherche, publiés ou non, émanant des établissements d'enseignement et de recherche français ou étrangers, des laboratoires publics ou privés. 
HIGH SPIN STATES OF THE ODD-ODD ${ }^{110}$ In NUCLEUS

R. Béraưd, A. Charvet, R, Duffait, M. Meyer, J. Genevey* ${ }^{*}$, J. Tréherne*, A. Genoux-Lubain ${ }^{*}$, (x)

F. Beck ${ }^{* *}$ and T. Byrski**.

Institut de Physique Nucléaire (IN2P3), Université Claude Bernard Lyon-1,

*33, boulevard du 11 novembre 1918, 69622 Vi ileurbanne Cedex, France.

* Institut des Sciences Nucléaires de Grenoble, (USMG et IN2P3) 53, me des Martyrs,

* 38026 Grenoble cedex France.

* Centre de Recherches Nucléaires de Strasbourg (IN2P3), 23, me du Loess, Cronenbourg,

67037 Strasbourg cedex, France.

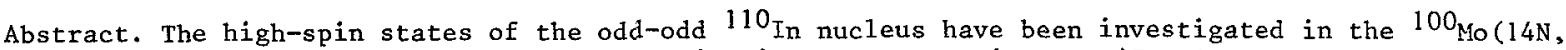
$4 \mathrm{n} \gamma$ ) reaction and observed up to $5.6 \mathrm{MeV}$ excitation energy. An intense $\Delta I=1$ cascade has been found from $7^{-}$to $14^{-}$and has been interpreted in the frame of the axial rotor + two quasiparticles model including Coriolis interaction.

\section{Introduction}

Recent studies have begun to explore the high spin structure of doubly odd-transitional nuclei in particular within the Au-Tl region ${ }^{1,2)}$ and around the shell closure $Z=50^{3,4)}$. This investigation is a part of a more systematic investigation of odd-odd silver and indium nuclei excited through heavy-ion reactions. The interest of oddodd nuclei such as indium is the possible existence of a so called "conflicting case" $\mathrm{u}^{5)}$ : the quasi-particles that give rise to collective bands in neighbouring odd-A nuclei have opposite behaviours in the framework of the rotor + quasiparticle model.

Namely, the $\pi g_{9 / 2}$ orbital leads to a coupled band structure $(\Delta I=1)$ whereas the $\nu h_{11 / 2}$ orbital accounts for decoupled bands $\Delta \mathrm{I}=2$. In 108 In (as in $196,198 \mathrm{Tl}$ ), such a conflicting case gives rise to a simple sequence of $\Delta I=1$ levels interpreted in the frame of the rotor + two quasi-particle model including Coriolis interaction.

\section{Experimental procedure and results}

The levels of 110 In have been excited using the ${ }^{100} \mathrm{Mo}\left({ }^{14} \mathrm{~N}, 4 \mathrm{n} Y\right)^{110}$ In reaction. Experiments were carried out by means of the Grenoble ISN cyclotron. The Mo target enriched to $97 \%$ in ${ }^{100}$ Mo consisted of a $1 \mathrm{mg} / \mathrm{cm}^{2}$ foil deposited on a lead backing of about $30 \mathrm{mg} / \mathrm{cm}^{2}$. Two Ge(Li) detectors having an efficiency of $15 \%$ and an $X$-ray

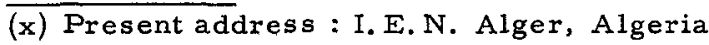

intrinsic $\mathrm{Ge}$ detector were used in the $\gamma$-ray experiments. The $y$-ray yield has been measured as a function of bombarding energy within the range $55-75 \mathrm{MeV}$. The maximum of ${ }^{110}$ In production occured at $62 \mathrm{MeV}$. This energy has been selected for all in beam experiments. A single $Y$-ray spectrum is shown in fig. 1. The main parasitic lines are those of ${ }^{109,110} \mathrm{Cd},{ }^{109} \mathrm{In}$ and ${ }^{107} \mathrm{Ag}$.

About $2.10^{7}$ biparametric $2048 \times 2048$ channel $Y-Y$ coincidence events have been recorded. The time resolution of prompt events was $15 \mathrm{~ns}$. Accidental coincidences (delay time of about $60 \mathrm{~ns}$ ) as also out of burst coincidences have been simultaneously recorded. No evidence for an isomeric state has been observed.

The angular distributions were measured at five angles ranging from $0^{\circ}$ to $90^{\circ}$ with respect to the beam direction. The normalization was deduced from spectra recorded by a fixed Ge(Li) detector. The linear polarization of ${ }^{110}$ In $\gamma$-rays was measured using the five germanium detectors Compton polarimeter described in reference 6 . The experimental value of the polarization $p$ is deduced from the coincidences scatterer plus horizontal analysers $\left(N_{H}\right)$ and scatterer plus vertical ones $\left(\mathrm{N}_{\mathrm{V}}\right)$ through the relation :

$$
\mathrm{p}=\frac{\mathrm{l}}{\mathrm{Q}(\mathrm{E})} \frac{\mathrm{N}_{\mathrm{V}}-\mathrm{N}_{\mathrm{H}}}{\mathrm{N}_{\mathrm{V}}+\mathrm{N}_{\mathrm{H}}}
$$

where $Q(E)$ is the polarization sensitivity of the 
polarimeter. The A2, A4 and $p$ coefficients extracted from those measurements are listed in table 1. A typical $\mathrm{N}_{\mathrm{V}}{ }^{-\mathrm{N}_{\mathrm{H}}}$ spectrum showing evidence for the polarization sign is displayed in fig. 2. The electron spectrum of 110 In has been measured with the help of the ISN orange spectrometer at Grenoble ${ }^{12)}$. The ${ }^{\alpha} K$ values extracted from

this experiment support the previous assignments deduced from angular distributions and polarization measurements. The level scheme deduced from available experimental evidence is given in fig. 3 . The ground state has been previously measured to be $7^{+} 7$ ). Above the g.s. and the first positive parity states is observed an intense cascade where states from $7^{-}$to $14^{-}$are connected with $\Delta I=1$ transitions. The El multipolarity of the $1337 \mathrm{keV}$ transition establishes the positive parity of the cascade starting with spin 12 at $3512 \mathrm{keV}$.

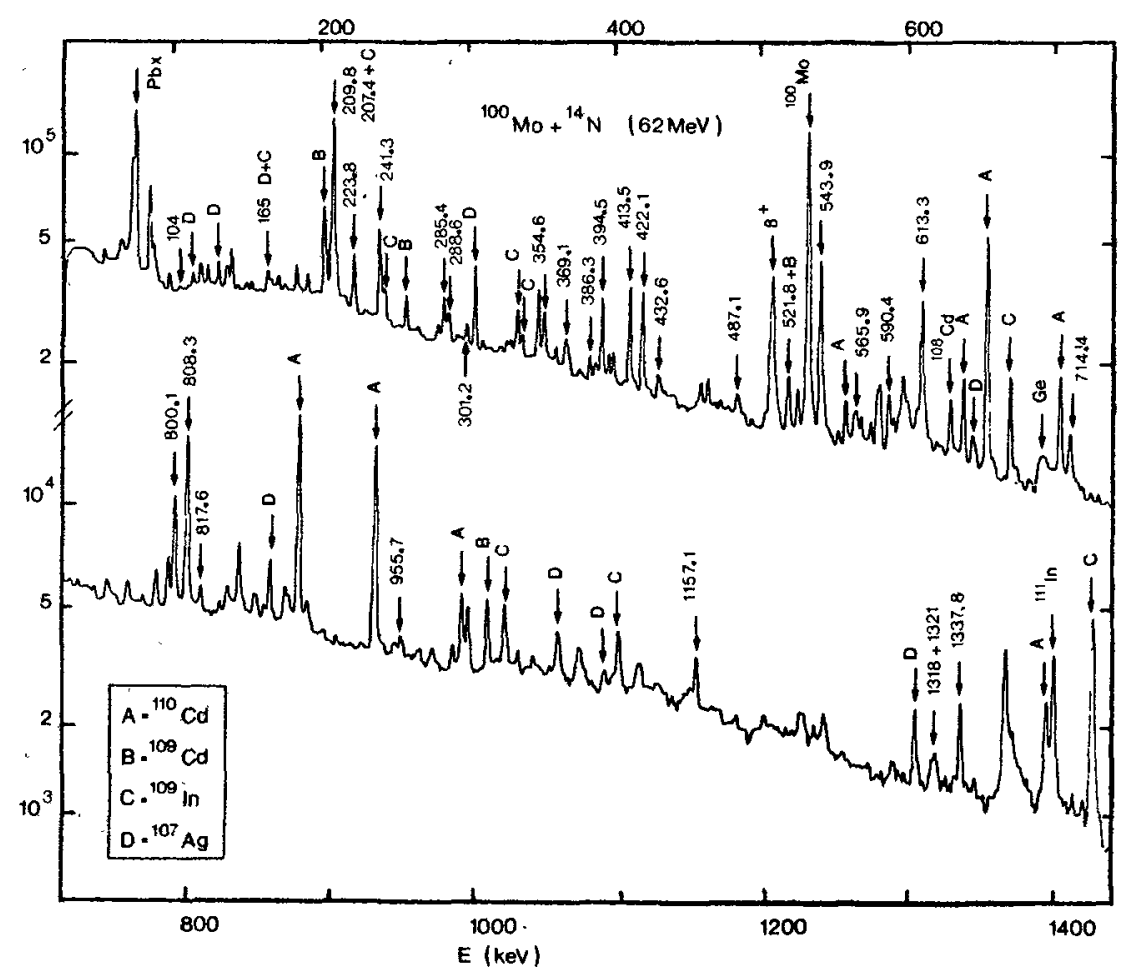

Figure 1 - $\gamma$-ray spectrum of the ${ }^{100} \mathrm{Mo}\left({ }^{14} \mathrm{~N}, 4 \mathrm{n} \gamma\right)$ reaction at $62 \mathrm{MeV}$

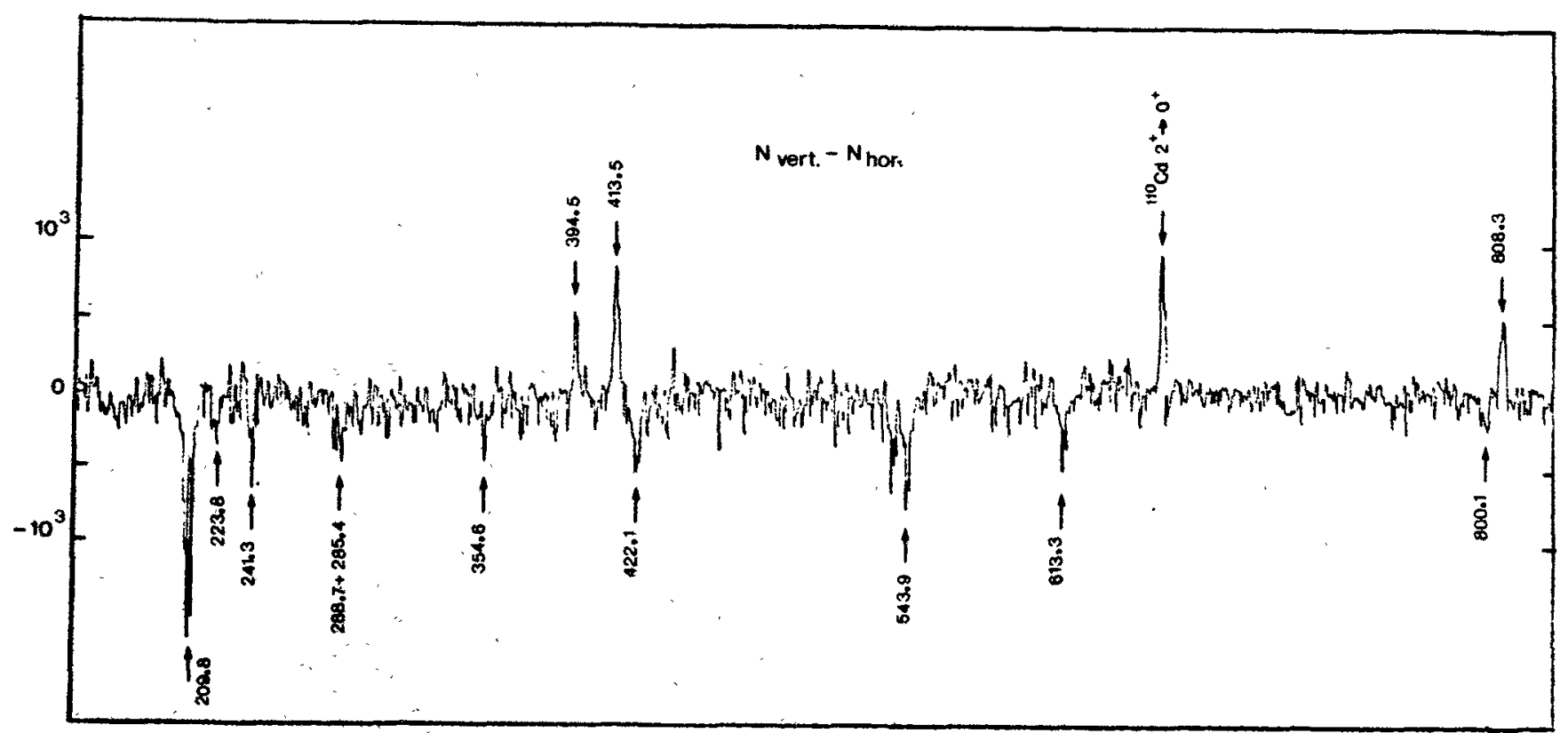

Figure 2 - A typical $\mathrm{N}_{\mathrm{V}}-\mathrm{N}_{\mathrm{H}} \mathrm{Y}$-ray spectrum. The positive (negative) peaks show positive (negative) linear polarization. 


\begin{tabular}{|c|c|c|c|c|c|}
\hline $\begin{array}{c}\mathrm{E}_{\mathrm{\gamma}} \\
(\mathrm{keV})\end{array}$ & \begin{tabular}{|lll}
${ }^{I}$ & & \\
& & \\
& & $b)$ \\
\end{tabular} & $A_{2}$ & $\mathrm{~A}_{4}$ & $P$ & $\begin{array}{l}\text { Multipo- } \\
\text { larity }\end{array}$ \\
\hline 8.2 & a) & & & & \\
\hline 104.5 & 2.5 & & & & \\
\hline 165.0 & 2.6 & & & & \\
\hline 207.4 & 8.0 & $-0.30(5)$ & $-0.02(5)$ & $-0.23(6)$ & M1 \\
\hline 209.8 & 100 & $-0.19(4)$ & $+0.01(4)$ & $-0.32(3)$ & M1 \\
\hline 223.8 & 11.2 & $-0.16(5)$ & $+0.05(5)$ & $-0.36(6)$ & M1 \\
\hline 241.3 & 34.5 & $-0.14(4)$ & $+0.02(4)$ & $-0.38(4)$ & Ml \\
\hline 285.4 & 13.8 & $-0.17(6)$ & $-0.06(6)$ & $-0.4(1)$ & M1 \\
\hline 288.6 & 7.2 & $-0.28(8)$ & $+0.14(7)$ & & M1 \\
\hline 301.2 & 5.8 & $+0.08(7)$ & $+0.08(7)$ & & \\
\hline 354.6 & 16.2 & $-0.20(6)$ & $+0.03(6)$ & $-0.52(9)$ & Ml \\
\hline 363.4 & 5.0 & $-0.03(10)$ & & & \\
\hline 367 & 1.5 & & & & \\
\hline 369.1 & 8.4 & $-0.65(12)$ & $+0.25(7)$ & $-0.34(8)$ & Ml \\
\hline 386.3 & 7.5 & & & & \\
\hline 394.5 & 26. & $-0.20(4)$ & $+0.01(4)$ & $+0.58(9)$ & El \\
\hline 413.5 & 41 . & $+0.33(3)$ & $+0.06(5)$ & $+0.73(9)$ & MI \\
\hline 422.1 & 35. & $-0.09(4)$ & $+0.02(4)$ & $-0.32(4)$ & Ml \\
\hline 432.6 & 6.3 & $-0.42(10)$ & $+0.14(10)$ & & (M1) \\
\hline 481 & 2 & $-0.36(15)$ & & & \\
\hline 487.1 & 5.3 & $-0.45(9)$ & $+0.30(15)$ & & (MI) \\
\hline 521.8 & 13.4 & $+0.20(5)$ & $+0.06(7)$ & $+0.21(16)$ & \\
\hline 543.9 & 62. & $-0.15(4)$ & $+0.05(4)$ & $-0.38(3)$ & Ml \\
\hline 565.9 & 4.3 & & & & \\
\hline 567.5 & 2 & & & & \\
\hline 590.4 & 11 & $-0.32(7)$ & $+0.10(6)$ & & (MI) \\
\hline 609 & 4 & & & & \\
\hline 613.3 & 52 & $-0.08(4)$ & $+0.03(4)$ & $-0.25(3)$ & MI \\
\hline 714.4 & 13 & $-0.10(6)$ & $+0.2(1)$ & $-0.74(20)$ & MI \\
\hline 754. & 5 & $-0.03(10)$ & & & \\
\hline 800.1 & 29 & $+0.37(3)$ & $+0.05(5)$ & $-0.80(25)$ & El \\
\hline 808.3 & 57 & $-0.15(4)$ & $+0.03(3)$ & $+0.42(5)$ & $\mathrm{E}_{1}$ \\
\hline 817.6 & 7 & & & & \\
\hline 955.7 & 3 & $+0.05(8)$ & & & . \\
\hline 1035. & 3 & $+0.6(2)$ & & & \\
\hline 1157.1 & 9 & $+0.33(6)$ & $-0.03(9)$ & & (E2) \\
\hline 1242 . & 4 & $-0.3(2)$ & & & \\
\hline 1318 & 2.4 & & & & \\
\hline 1321 & 2.8 & & & & \\
\hline 1337.8 & 6 & $-0.26(10)$ & $-0.1(1)$ & $+0.9(4)$ & El \\
\hline
\end{tabular}

Table 1 - Energies, intensities, angular distribution coefficients, linear polarization and multipolarity of $\mathrm{y}$-rays assigned to $110 \mathrm{In}$.

a) This very low energy transition has not been observed with an intrinsic Ge X-detector because of its large conversion coefficient but its existence is required to explain the coincidence results

b) Relative $\gamma$-ray intensities at $62 \mathrm{MeV}$ bombar ding energy corrected for angular distribution. Energy (intensity) uncertainties are about $0.2 \mathrm{keV}$ $(10 \%)$ for intense transition $\left(I_{Y}>20\right)$ and $0.5 \mathrm{keV}$ $(20 \%)$ for the other ones.

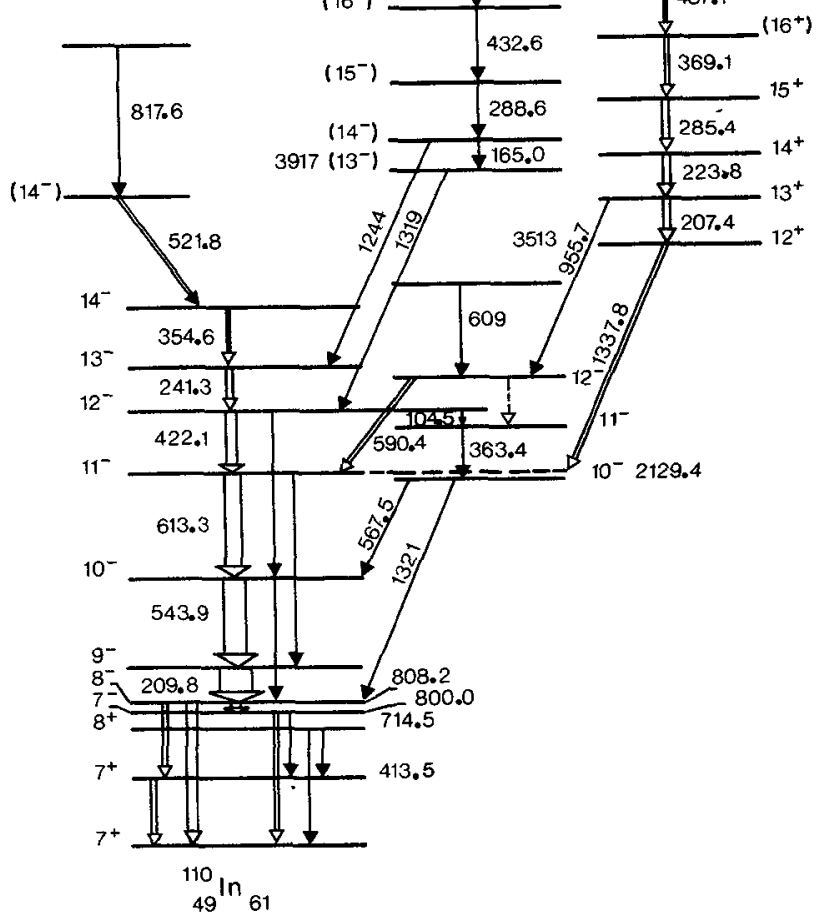

Figure 3 - Level scheme of ${ }^{110}$ In obtained from this study
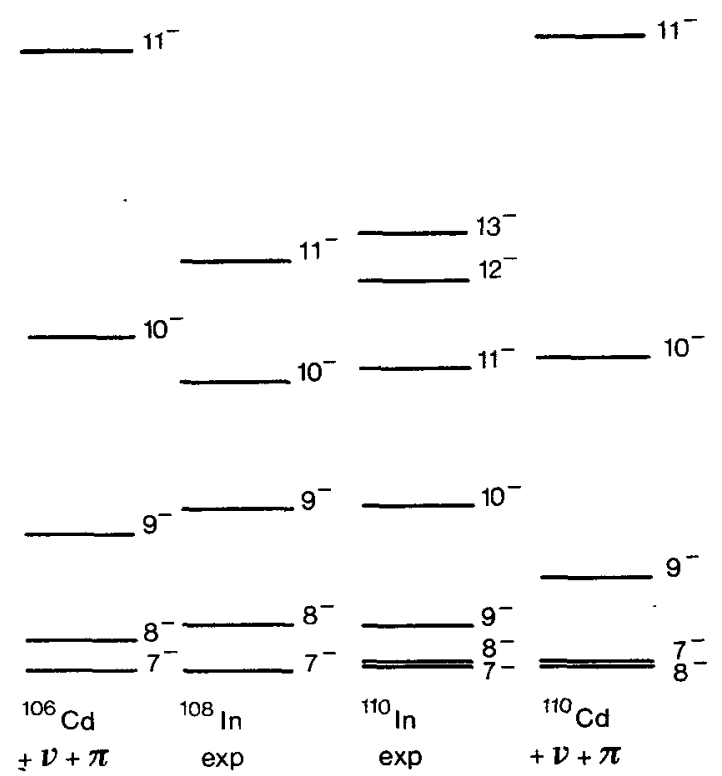

Figure 4 - Experimental negative parity states in 108 In and 110 In compared with the theoretical ones. 


\section{Discussion}

The more striking feature is the presence of an intense $\Delta I=1$ cascade of negative parity levels as it has been observed in ${ }^{108} \mathrm{In}$. Due to the presence of levels with spins higher than 10, this scheme cannot be explained as $\pi g_{g / 2} \nu_{11 / 2}$ multiplet states 8). Potential energy calculations 9 ) for odd indium isotopes indicate a small prolate equilibrium deformation. Therefore, as in ${ }^{108}$ In and in odd-odd thallium, we apply the two quasi-particlestaxial rotor model including Coriolis interaction. The quasiparticle energies of neutron and proton, the pairing coefficient $u_{j}$ and the deformation have been extracted from constrained H.F. calculations on ${ }^{106,110} \mathrm{Cd}$ presented in a recent paper ${ }^{10}$. These band mixing calculations have been performed by taking into account all proton and neutron orbitals situated within one MeV on both sides of the Fermi level. The residual interaction between the valence proton and neutron has been neglected in our calculation. Comparison between experiment and theoretical calculations is given in figure 4 for both ${ }^{108}$ In and 110 In. The model accounts for the special nearness of the $7^{-}$ and $8^{-}$states in 110 In.

The experimental sequence is relatively well reproduced except a slight energy expansion of the calculated level scheme; it should be noted that no free adjustable parameter is enclosed in our calculations. The inclusion of a variable moment of inertia or the attenuation of the Coriolis interaction should lead to a bunching of the states ${ }^{11}$ ). The coexistence of $E 2$ and $M 1$ transitions accounts that this sequence looks like a rotational band based on the 8 level composed predominantly of $K=6,7,8$ bandmixing arising from $v_{11 / 2}\left(\Omega_{n}=3 / 2,5 / 2,7 / 2\right)$ $\pi g_{9 / 2}\left(\Omega_{p}=9 / 2\right)$ states. The positive parity band built on the $12^{+}$state located at $3512 \mathrm{keV}$ cannot be explained in this pure two-quasi particles + rotor mode1.

In conclusion the Coriolis interaction appears to be dominant also in doubly odd transitional nuclei in presence of high-j unique parity orbital, on the assumption that the proton-neutron interaction is weak.

\section{References}

1) Kreiner A. J., Fenz1 M., Lunardi S., and Mariscotti M. A.J., Nuc1. Phys., A 282,(1977) 243

2) Neskakis A., Lieder R. M., Beuscher H., Gono Y., Haenni D. R., Muller-Veggian M., and Mayer-Boricke C., Phys. Lett., $80 \mathrm{~B}$, (1979) 194

3) Elias N., Thèse Doct. Spécialité 3ème Cycle, Lyon, (1979) (Lycen-7942)

Charvet A., Beraud R., Duffait R., Elias N., André S., Genevey J., Tedesco S., Treherne J., Beck F. and Byrski T. (to be published)

4) Beraud R., Charvet A., Duffait R., Meyer M., Genevey J., Treherne J., Beck F., Byrski T. Contribution to this conference

5) Toki H., Yadav H. L., and Faessler A., Phys, Lett., 66 B, (1977), 310

6) Beck F., and Henck R., Rapport Annuel 1979, C.R.N. Strasbourg

7) Lederer C.M. and Shirley V.S., "Table of Isotopes" 7th Ed., J. Wiley \& Sons, New-York

8) Rabenstein D., and Harrach D., Nucl. Phys., A 242, (1975), 189

9) Dietrich W., Bäcklin A., Lannegärd C.O. and Ragnarsson I., Nucl. Phys., A 253, (1975), 429

10) Meyer M., Danière J., Letessier J. and Quentin P., Nucl. Phys., A 316, (1979), 93

11) Ludziejewski J., Bron J., Hesselink W. H. A., Kalshoven A. W. B., Peker L.K., Van Poelgeest A., Verheul H., and de Voigt M. J.A., in Proc. of the Intern. Conf. on Band-Structure and Nuclear Dynamics, New Orleans, Feb.28March 1, 1980, p. 121

12) Tedesco S., Thèse Doct. Spéc. 3ème Cycle, Grenoble, (1979) 